\title{
BMJ Open CoronaCare study protocol: an ethnographic study of the risks to and potential for social health during the COVID-19 pandemic
}

\author{
Joshua Paul (D) , ${ }^{1}$ Sibille Merz (D) , ${ }^{1}$ Andreas Bergholz (D) , ${ }^{1,2}$ Franziska König (D) , \\ Christian Apfelbacher (10, ${ }^{3}$ Astrid Eich-Krohm (D) , ${ }^{3}$ Julia Weigt, ${ }^{3}$ \\ Christine Holmberg (iD) ${ }^{1,2}$
}

To cite: Paul J, Merz S, Bergholz A, et al. CoronaCare study protocol: an ethnographic study of the risks to and potential for social health during the COVID-19 pandemic. BMJ Open 2021;11:e048212. doi:10.1136/ bmjopen-2020-048212

- Prepublication history and additional supplemental material for this paper are available online. To view these files, please visit the journal online (http://dx.doi.org/10.1136/ bmjopen-2020-048212).

Received 06 January 2021 Accepted 06 September 2021

D) Check for updates

(c) Author(s) (or their employer(s)) 2021. Re-use permitted under CC BY-NC. No commercial re-use. See rights and permissions. Published by BMJ.

${ }^{1}$ Institute for Social Medicine and Epidemiology, Brandenburg Medical School, Brandenburg an der Havel, Germany

${ }^{2}$ Faculty of Health Sciences, Brandenburg Medical School Theodor Fontane, Brandenburg an der Havel, Germany

${ }^{3}$ Otto von Guericke University Magdeburg, Magdeburg, Germany

Correspondence to

Dr Joshua Paul;

joshua.paul@mhb-fontane.de

\section{ABSTRACT}

Introduction German government regulations such as physical distancing and limited group numbers, designed to curb the spread of COVID-19, have had far-reaching consequences for the very foundations of social life. They have, to name only a few, transformed greetings and goodbyes, blurred private and public worlds, and complicated basic communication with mandatory mask wearing. The ethnographic study CoronaCare investigates how these sociopolitical measures affect social health, a form of health which unfolds through and across social relations. It explores how caring as a fundamental human activity and one integral to sustaining social health is impacted when in-person and person-to-person contacts are restricted and everyone is radically redefined as at risk from others and a risk to others. It explores care relationships, relationships involving the giving or receiving of care in everyday life, institutional settings such as an assisted living facility, and informal settings, such as a housing block. Inside of the pandemic, relationships are a pivotal site at which the negotiation of caring and risk is intensified and where the consequences for social health and social life more generally are pronounced.

Methods and analysis This ethnographic project aims to understand the tensions that arise in the lives of individuals and communities living under the sociopolitical regulations and to analyse the tacit forms of practice that individuals and communities develop to uphold social health. Fueled by citizen science, the ethnography uses a variety of methods namely telephone and video interviews with 60-70 research participants, the collection of ethnographic material including video and audio diaries, storyboards, first-person camera footage, photographs and a survey to enrich the sample description based on the Copenhagen Psychosocial Questionnaire. The analysis will draw on elements of grounded theory and through the aid of the qualitative software MAXQDA it will rigorously document and explain how the social regulations are (re) shaping our ability to be cared for and to care for one another. The survey data will be analysed through the use of the quantitative software programme $\mathrm{R}$.

Ethics and dissemination The ethics committee of the Brandenburg Medical School Theodor Fontane has approved the project (E-01-20200605). The dissemination strategy includes publications in medical, sociological
Strengths and limitations of this study

- Data collection is limited to the German context.

- The full range of ethnographic methods is limited by regulations mandating physical distancing.

- A variety of research methods including interviews, ethnographic materials and a standardised questionnaire on work load (Copenhagen Psychosocial Questionnaire) richly capture how the regulations are (re)shaping social life and impacting social health.

- 1.5 years of longitudinal data will provide a comprehensive evidence base for developing research informed recommendations for future pandemic preparedness.

- The ethnography investigates care relationships, and social health in both institutional and private settings.

and research methods journals, as well as a stakeholder discussion with political and civil society leaders where the research team will present its recommendations for future pandemic preparedness.

\section{INTRODUCTION}

Government responses to the COVID-19 pandemic, undergirded by an epidemiological and biomedical rationale, have predominantly focused on containing the spread of Sars-CoV-2 in order to maintain the physical health of national populations. Of principle concern has been uncovering the aetiology of the virus, understanding the routes and dynamics of its transmission, its prevalence, incidence, lethality, the human immune response, its clinical diagnosis and treatments, and most urgently the race to develop a vaccine. Less discussed and considered, especially in the early phases of the outbreak, was how a state of exception regulating the entirety of social life from how we greet one 
another, to how we shop, to how (or if) we work has suddenly displaced us from the relationships, everyday routines, communities and forms of connectedness integral to our lives and well-being. ${ }^{1}$ An emerging body of research has already charted the social and psychological aspects of the pandemic; forecasting substantial increases in anxiety and depression, substance use, loneliness and domestic violence, ${ }^{2}$ showing social isolation leads to chronic loneliness and boredom, with detrimental effects on physical and mental well-being, ${ }^{3}$ how the pairing of uncertainty and isolation has compounded mass panic and anxiety, ${ }^{4}$ the differential socioeconomic distribution of infection and vulnerability, ${ }^{5}$ how public health resources might be ethically allocated, ${ }^{6}$ and the frequency of adverse psychological outcomes in the form of burnout, anxiety, fear of transmitting infection, feeling of incompatibility, depression, increased substance dependence and post-traumatic stress disorder particularly among older people, their caregivers, psychiatric patients and marginalised communities. ${ }^{7}$

\section{Study purpose and aims}

CoronaCare is an ethnographic project funded by the German Ministry of Education and Research that explores how the sociopolitical measures to contain the virus' spread affect the everyday lives of people living in Germany. In other words, the project empirically examines social health and the practices people use to sustain it in the changed sociocultural circumstances of the pandemic. With these practices taken as a central object of investigation, the ethnography embeds (although conforming to Corona distancing regulations) the researcher in the ongoing interactions of the research participants through, for example, longitudinal interviews and our monthly newsletter featuring voluntary participant contributions in order to understand and explain partiticpants lived experience. In interviewing, observing and participating in the lives of our research participants we are able to capture meanings, behaviours, intention and interactions that are often overlooked in other methods that are more distant such as surveys or more contrived such as experiments. In short, ethnography offers a compelling rationale as the ideal research methodology for uncovering the empirical data that emerges when people express their most pressing and ordinary concerns and experiences in relation to social distancing, mask wearing, numerically limited social gatherings, home office and other regulations.

CoronaCare contributes a fine-grained socioanthropological perspective to this knowledge through four research aims: (1) to understand the tensions, understood as the difficulties and challenges that arise in the lives of individuals and communities living under the sociopolitical regulations; (2) to analyse the tacit forms of practice that individuals and communities develop to uphold social health; (3) to examine how caregivers in informal and institutional settings negotiate the tensions in their care relationships with a strong focus on social isolation and the risk of infecting others and being infected themselves; and (4) to critically analyse how care receivers experience these tensions, with particular attention to social isolation and the unavoidable infection risks introduced into the relationship with their caregivers.

\section{Theoretical background}

The theoretical background informing the study design centres on how the pandemic has reconfigured social life through the governing logic that everyone is simultaneously at risk of infection and a risk for infecting others. Omnipresent in public health rhetoric, risk $\operatorname{logics}^{8}$ call on the public to manage their risk exposure, to become 'knowledgeable' about the sources, nature and consequences of being at risk and a risk, and demand vigilant observance to a raft of preventive measures. Beck ${ }^{8}$ argues risk logics reflect the trend towards individualisation and so encourage individuals to think of themselves as exercising a high level of control over the extent to which we expose themselves to danger and consequently put themselves at risk. Risk logic then defines risk as a human responsibility, both in its production and management. This is in sharp contrast to premodern perspectives where risk was equated with cosmic fate or destiny. This demanding labour entails the close monitoring and regulation of one's decisions and actions and the constant recognition of oneself and others as "vulnerable'. ${ }^{9}$ The pandemic has intensified the dispersal of risk into every corner of social life and redefined practices that normally connect people and communicate care, such as greeting a friend with a warm hug, into sources of worry. 'Risk worries', irreducible to a rational calculation of danger, draw attention to the complex amalgam of emotions, interests and values situated inside of experience that are likely to profoundly influence social interactions as they exemplify an insoluble dilemma. ${ }^{10}$ How can one participate in the intimacies of social life so central to health while also observing government directives with respect to physical distancing, mask wearing or home isolation?

With these tensions forming the research focus, CoronaCare explores how people during the pandemic negotiate the personal and societal tensions stemming from the sociopolitical regulations. It does so with a particular focus on social health, a concept we derive from the rough sketch offered by Kleinman and Kleinman ${ }^{11}$ but enrich descriptively, extend theoretically and anchor empirically. Social health has diverse meanings within different contexts. Indeed, most measures of the social health of individuals curiously do not employ the word 'health', but speak instead of 'well-being', 'adjustment', 'performance' or 'social functioning'. Cho et $a l^{12}$ have recently written a comprehensive review of existing thinking on social health which roughly clusters around two analytical lenses, namely the micro and the macro. CoronaCare goes beyond these common understandings. We draw on Kleinman's concept of social health as meaningful relationships ${ }^{13}$ in advancing a concept that stresses its inescapably complex and elusive ${ }^{14}$ and affective dimensions. ${ }^{15}$ 
Kleiman outlines social health as the political and social structures which enable the leading of a moral life. From such a perspective, CoronaCare aims to move our conceptual understanding of social health away from how 'the social' impacts biological and psychological health as a bounded and quantifiable entity towards an understanding of health as lived social practice, constituted in and through meaningful human interaction. Through this concept CoronaCare will explore how health is made and remade in the social contexts and through the sociopolitical structures that social actors inhabit. CoronaCare understands health beyond biomedical and risk paradigms as itself socially sustained, that is inescapably comprised of meaningful, fundamentally human interactions. ${ }^{16}$ Social life is the space for the interactions that meet our basic needs and it is through social relationships that we derive the care giving and care receiving that sustains life. Being cared for and caring for others is a fundamental part of human life. ${ }^{17}$ Caring, both in the technical and emotional sense (ie, taking care of someone who cannot do it him or herself, and caring about or having an emotional orientation towards someone), equips us with the moral and practical wisdom for living in networks and communities. Caring is a reciprocal, taken-for-granted activity that is culturally embedded in being attuned to the other. It occurs in the reproductive labour that literally sustains life such as preparing meals for an elderly relative, helping him/her to eat and get dressed as well as in the minutia of social life: in how we greet one another, how we show affection or communicate empathy through a gentle touch. Caring is, in short, the physical and emotional work that sustains our social health. It is precisely such taken-for-granted physicalsocial activities that are jeopardised by the regulations. ${ }^{18}$ Ultimately, the CoronaCare project seeks to map out the various challenges and difficulties that the sociopolitical regulations present for social health and care. Moreover, the project will use longitudinal ethnographic data to derive evidence-based recommendations for future pandemic planning and preparedness.

\section{METHODS AND ANALYSIS \\ Study design}

CoronaCare is an ethnographic study employing qualitative and quantitative methods to investigate how the pandemic, in reframing everyone as both a-risk for and at-risk of infection, impacts on social health. More specifically, it explores how the regulations effect the taken-for-granted care activities of everyday life and how such activities (might) change over time and potentially develop into new forms of caring relationships. Ethnography signifies a comprehensive methodology for investigating everyday practices ${ }^{19}$ of communities and societies. The methodological premise is that researchers learn about people's lives from their own perspective and within the context of their own lived experience. Studying social and cultural phenomena in action captures the complexity of human lives which cannot be reduced to a sterile laboratory experiment. The number of different research techniques and methods used in the project form a complex research strategy that matches the complexity of the object of study. Ethnographic practice provides a close-up, real time space for observing social life, developing and extending theory, generating concepts and illuminating empirical patterns. ${ }^{20}$ Through longitudinal video and phone interviews, a research newsletter featuring voluntary participant contributions, video and audio diaries, photographs, storyboards, first-person camera footage, drawings and autoethnographic journals from the research team, the project is immersed in the lives of others in order to uncover and analyse direct experiences of this regulated social world and to illuminate locally relevant strategies for caring. In short, the research team observes and experiences events, behaviours, interactions, representations and conversations that are the manifestations of society in action. Through this ethnographic granularity with its sharp resolution of the needs and concerns of people on the ground, as well as a keen attention to their sense of the complex ecology of infection, health and risk CoronaCare investigates pandemic life in the context of people's homes, workplaces and relationships. ${ }^{21}$ To complete the ethnography inside of the restrictions, the research team has drawn on citizen science models, which turn citizens into scientists documenting the lived experience of the pandemic through the various methods detailed below. The ethnography reflects the European Citizen Science Association's ${ }^{22}$ principles which maintain citizens should actively contribute to increasing the body of academic knowledge. The project seeks to deepen the reservoir of empirical data on social health, build community capacity for social health protection, foster more equal relationships between researchers and citizens, fill knowledge gaps, challenge the exclusion of experience in official accounts and offer recommendations for health policy.

\section{Sample}

The study sample consists of 70 persons living in Germany who provide longitudinal insights into their everyday lives. The sample size of 70 reflects both the intention of obtaining a sizeable sample from which patterns can be identified and recommendations derived as well as a realistic appraisal of what is methodogically and analytically possible given limitations to the size of the research team and the December 2021 deadline. Preliminary calls to chronicle one's life began in March 2020 during the first lock down and concluded in May 2021. CoronaCare uses two sampling strategies. During the initial phase in March 2020, the research team used its existing social and professional networks. Recruitment was structured along two rationales. First, participants were recruited around established sociodemographic characteristics (ie, age, gender, migration background, etc) in order to build a diverse sample. Second, the research team sampled strategically with specific attention to how the pandemic 
unfolded inside of Germany including, for example, regional outbreaks, impacts on employment, and living situation (ie, alone, with others, etc). The sample is drawn from across all the different geographic regions (Bundeslände or federal states) of Germany including formerly east German states and includes a mixture of large, medium and small population cities and villages. Early in the pandemic, we placed specific emphasis on BadenWürttemberg as this region experienced high incidence rates. While a thorough review of the course and severity of COVID-19 is beyond the scope of this study protocol, the German government has produced a concise and continuously updated timeline of its unfolding. ${ }^{23}$ Additionally, existing professional networks in Berlin, Brandenburg and Saxony-Anhalt were included in the sample. With particular focus on care situations, we aim to include at least 10 nursing professionals from long-term care facilities and 10 informal caregivers, as well as at least 10 residents of different nursing homes.

\section{Recruitment}

Recruitment used key informants, community assessments and stakeholder mapping, that is, key institutions in particular fields that were approached. This targeted strategy allowed the research team to complete the above described theoretical sample.

\section{Data collection}

Qualitative, semistructured interviews are being conducted using a schedule of questions devised by the research team. Interview themes include: everyday experiences of limited social interaction and social distancing; individual strategies of coping with the changes to social interaction stemming from physical distancing, compulsory masking, restricted groups; and participants' perceptions of risk and risk worries vis-à-vis the ever-present danger of being infected as well as infecting others. The interviewer uses the schedule of questions which has a default wording and order. The wording and order, however, will often be substantially modified based on the flow of the interview. Additional unplanned questions and probes might also be asked in order to follow-up on what the interviewee communicates. The interviews are digitally recorded on a mobile dictation machine (DM720; Olympus, Hamburg, Germany).

For the collection of voluntary ethnographic data participants receive an 'ethnographic manual' introducing and describing the different techniques they can use to document their own lives. The manual contains ideas for possible thematic areas to be covered (family life, work life, everyday experiences) and the mediums through which they can be documented: video and audio diaries, storyboards, first-person camera footage, photographs and contributions to the participant newsletter. Suggestions for contributions include constructing a story or narrative about their lives, or recording homemovie style footage of family and social events. Participant diaries (semistructured or unstructured) offer a space for more free-flowing reflection around experiences of the pandemic. Participants are invited to use their smart phones or another device to document and reflect on everyday experiences that they might not otherwise notice or remember. Ultimately, these textured forms of data enable the research team to access areas of everyday or private life that remain otherwise inaccessible. Participants are invited to complete and later explain inside of an interview, a story board. Originally sourced from film making, storyboarding involves planning a comic strip that tells a story with drawings accompanied by short descriptions. Participants are asked to storyboard on their experience with a person or people (ie, friends, family, colleagues, doctors), in a particular place (ie, home, work, university, hospital), and their associated feelings (ie, happy, lonely, loved, anxious). The activity introduces another medium through which participants can share their inner-worlds in the face of social distancing regulations. Using wearable cameras, participants are able to capture participation in dance-alongs, sing-alongs, eat-alongs and the like. Regular telephonic contact and check-in meetings with participants are maintained by the research team as well as through a monthly newsletter. The aim of the newsletter is to engage the participants in a more dynamic, hands-on way in accordance with our citizen science approach. Newsletters will contain participant contributions such as diary entries in response to the question of the week as well as interactive elements such as setting a new research focus for the month.

To ensure data protection inside of the work environment those participants who are formally recruited through care homes or who work in convalescent homes or in out-patient care will only participate in interviews. Additional interview themes for this part of the study include the working conditions in institutionalised care settings, the emotions connected to the heightened risk of infecting patients, the heightened risk of employee infection given the lack of personal protective equipment, and how maintenance of care practices are upheld when physical isolation is recommended. As care receivers in institutional settings are most isolated by regulations, they may experience the greatest risk to social health. Therefore, additional interview themes focus on the potentially fragile situation of institutionalised care receivers and their strategies to maintain social health (or not) alongside caring relationships within the institutions. Themes covered include how patients manage the impact on their relationships with their carer and family or friends during the closure of convalescent homes and the overall minimisation of physical contact.

Finally, a German, pandemic modified version of the Copenhagen Psychosocial Questionnaire (COPSOQ), ${ }^{24}$ will record psychosocial risk factors and conditions specific to the pandemic by operationalising the most relevant psychosocial domains (eg, work-family conflict). Considering the substantial scientific evidence on their relation with health, these dimensions are useful for the project in analysing how risk is experienced at work. The 
COPSOQ is completed online on SoSciSurvey and for participants lacking digital means, via post. For a descriptive assessment of the sample, the research team have amended the COPSOQ to include data on participants' socioeconomic status, living situation, age, gender and place of residence. Ahead of the first interview, the interviewer discusses the information sheet with the participant and clarify any open questions. Consent forms are sent via post to participants who sign and return them using the enclosed prepaid envelope. The COPSOQ material will be analysed by the software programme $\mathrm{R}$ and will be used to supplement the qualitative data with empirical data and variables such as socioeconomic status, living situation and so on to describe the study sample.

\section{Data processing and analysis}

Audio recordings are transferred to and stored in an access-protected project folder accessible only by project staff. The audio data are transcribed by the project team on a password protected server at the institute. Transcription is aided by the software f4transkript (dr. dresing \& pehl GmbH, Marburg, Germany). Once an audio file has been transcribed and personal information removed, the pseudonymised transcript is stored in the access-protected project folder. The researchers will continue to work with the pseudonymised transcripts. Computer-assisted coding will be performed using MAXQDA V.20 (VERBI, Berlin, Germany).

Data analysis will be conducted in a detailed, questionfocused manner combining elements of a grounded theory approach ${ }^{25}$ and thematic analysis. Grounded theory is a systematic 'ground-up' analysis of data with the aim of generating theory that explains a context or phenomenon. The focus of analysis lies on the tensions that arise through the pandemic on everyday life to capture what is missing and develop an empirical understanding of social health. Text passages and ethnographic materials that relate to aspects of social health will be identified and analysed (see online supplemental material). Grounded theory's systematic manner of coding, particularly initial line-by-line coding is useful for investigating study participants' experiences of the pandemic. Through this inductive method the research team will initially through systematic coding and later through constant comparison construct relevant themes for the individual cases, ${ }^{26}$ contrasting where possible observational and interview data and bringing them into dialogue with one another. A data codebook will be generated using inductive methods following grounded theory and will initially be structured around recurrent themes in the data set. It will form the map of the data and will be further analysed and advanced into an analytical framework through the use of intext memos and weekly data workshops inside the research team. Data codes from cases will then be abstracted to form key concepts and categories explicating how our research participants manage uncertainty, risk and the transformation of caring relationships in times of crisis.

\section{Patient and public involvement}

How was the development of the research question and outcome measures informed by patients' priorities, experience and preferences?

They are no patients in the study. However, the interview participants are given wide scope in semistructured interviews to detail their own priorities, experience and preferences. Additionally, they can voluntarily submit a range of ethnographic material, as detailed above, to describe and explain their own priorities, experiences and preferences. The second and third interviews also offer the participants the opportunity to draw on this material and in a sense to set their own focus for the discussion.

How did you involve patients in the design of this study?

Research participants are involved as citizen scientists, participating in interviews and contributing their own voluntary accounts through the methods detailed above such as diaries, videos, photos and participating in the research newsletter.

Were patients involved in the recruitment to and conduct of the study? No.

How will the results be disseminated to study participants? The participants will be notified of the pandemic preparedness findings.

For randomised controlled trials, was the burden of the intervention assessed by patients themselves?

Not applicable.

Patient advisers should also be thanked in the contributorship statement/acknowledgements.

Not applicable.

\section{ETHICS AND DISSEMINATION}

CoronaCare has been approved following a comprehensive review by the Brandenburg Medical School Ethics Committee. Beyond this formal review, the team's overarching ethics value the mutual respect, dignity and connectedness between researchers and those researched. The team is guided by the ethical principle of being aware of one's own role and impact on relationships and treating participants as whole people rather than as subjects from which to extract data.

Informed consent is initially take verbally before the interview and later in written form to systematically ensure that participants are knowingly participating. Participants will then sign and date the written agreement that explains the project, allows for withdrawal from the research, and clarifies that these risks and benefits have been explained. On return, the signed consent form will be securely stored in an access-limited filing cabinet in a locked office on the Brandenburg Medical School campus. To safeguard confidentiality, all elements that might indicate the participants' identities will be removed from the research records and each participant will be assigned a pseudonym. Additionally, all ethnographic data will be stored in passwordprotected digital folders, and the data itself scrubbed 
of identifying elements. Participation in the research project is voluntary and no compensation for study participation is provided.

The dissemination strategy includes several publications in medical, sociological and research methods journals. We plan to publish in both English and German which does not present a difficulty as the team is comprised of native speakers in both languages. Additionally, as the project is an engaged public health project the research team will host a stakeholder discussion with political and civil society leaders. This event will draw on our theoretically informed and empirically engaged findings to present research developed recommendations and support measures for communities and individuals. Support materials will be made broadly available and presented in lay language (eg, leaflets, and online resources accessible through municipal level websites).

Acknowledgements We would like to thank the two peer reviewers, namely Dr. A Kim, of Massachusetts General Hospital and Dr. Christine Morton of Stanford University for their constructive feedback on an early version of this article. We would also like to thank the journal editors especially Dr. Andy McLarnon for their scholarly and adminstrative work.

Contributors JP drafted the article with significant input from $\mathrm{CH}$ and SM. CA, AE$K, J W, A B, F K$ and $A B$ have read, made suggestions and agreed to the final article.

Funding This study was funded by the German Ministry of Education and Research (Grant Number 01KI20117). We would also like to acknowledge funding from the Brandenburg Medical School Theodor Fontane's (MHB) Open Access Publication Fund which is supported by the German Research Association (DFG).

Competing interests None declared.

Patient consent for publication Not applicable.

Provenance and peer review Not commissioned; externally peer reviewed.

Supplemental material This content has been supplied by the author(s). It has not been vetted by BMJ Publishing Group Limited (BMJ) and may not have been peer-reviewed. Any opinions or recommendations discussed are solely those of the author(s) and are not endorsed by BMJ. BMJ disclaims all liability and responsibility arising from any reliance placed on the content. Where the content includes any translated material, BMJ does not warrant the accuracy and reliability of the translations (including but not limited to local regulations, clinical guidelines, terminology, drug names and drug dosages), and is not responsible for any error and/or omissions arising from translation and adaptation or otherwise.

Open access This is an open access article distributed in accordance with the Creative Commons Attribution Non Commercial (CC BY-NC 4.0) license, which permits others to distribute, remix, adapt, build upon this work non-commercially, and license their derivative works on different terms, provided the original work is properly cited, appropriate credit is given, any changes made indicated, and the use is non-commercial. See: http://creativecommons.org/licenses/by-nc/4.0/.

\section{ORCID iDs}

Joshua Paul http://orcid.org/0000-0003-3732-6357

Sibille Merz http://orcid.org/0000-0001-9967-6462

Andreas Bergholz http://orcid.org/0000-0002-0953-1954

Franziska König http://orcid.org/0000-0003-1148-0268

Christian Apfelbacher http://orcid.org/0000-0003-3805-8219

Astrid Eich-Krohm http://orcid.org/0000-0003-3456-1028

Christine Holmberg http://orcid.org/0000-0002-8852-4620

\section{REFERENCES}

1 Waldinger RJ, Cohen S, Schulz MS, et al. Security of attachment to spouses in late life: concurrent and prospective links with cognitive and emotional wellbeing. Clin Psychol Sci 2015;3:516-29.

2 Galea S, Merchant RM, Lurie N. The mental health consequences of COVID-19 and physical distancing: the need for prevention and early intervention. JAMA Intern Med 2020;180:817-8.

3 Banerjee D, Rai M. Social isolation in Covid-19: the impact of loneliness. Int J Soc Psychiatry 2020;66:525-7.

4 Usher K, Durkin J, Bhullar N. The COVID-19 pandemic and mental health impacts. Int J Ment Health Nurs 2020;29:315-8.

5 Hatef E, Chang H-Y, Kitchen C, et al. Assessing the impact of neighborhood socioeconomic characteristics on COVID-19 prevalence across seven states in the United States. Front Public Health 2020;8:571808.

6 Berlinger N, Wynia M, Powell T. Managing uncertainty, Safeguarding communities. Guiding Practice 2020;12.

7 Dubey S, Biswas P, Ghosh R, et al. Psychosocial impact of COVID-19. Diabetes Metab Syndr 2020;14:779-88.

8 Beck U. Risk society: towards a new modernity. London; Newbury Park, Calif: Sage Publications, 1992.

9 Petersen AR. The new public health: health and self in the age of Risk/Alan Petersen and Deborah Lupton. London; Thousand Oaks: Sage Publications, 2000.

10 Röhr S, Müller F, Jung F. Psychosoziale Folgen von Quarantänemaßnahmen bei schwerwiegenden CoronavirusAusbrüchen: ein rapid review. Psychiatr Prax 2020;47:179-89.

11 Kleinman A, Kleinman J. The transformation of everyday social experience: what a mental and social health perspective reveals about Chinese communities under global and local change. Cult Med Psychiatry 1999;23:7-24.

12 Cho SM, Park C-U, Song M. The evolution of social health research topics: a data-driven analysis. Soc Sci Med 2020;265:113299.

13 Kleinman A. Social origins of distress and disease: depression, Neurasthenia, and pain in modern China. New Haven: Yale University Press, 1986.

14 Antonovsky A. Unraveling the mystery of health: how people manage stress and stay well / Aaron Antonovsky. 1st edn. San Francisco, Calif: Jossey-Bass Social and Behavioral Science Series, 1987.

15 Duff C. Assemblages of Health: Deleuze's Empiricism and the Ethology of Life. Dordrecht: Springer, 2014.

16 Kleinman A. From illness as culture to caregiving as moral experience. N Engl J Med 2013;368:1376-7.

17 Wilkinson I, Kleinman A. A passion for society: how we think about human suffering. Oakland, California: University of California Press, 2016.

18 Deutsche Gesellschaft für Pflegewissenschaft: S2 Leitlinie für Soziale Teilhabe und Lebensqualität in der stationären Altenhilfe unter den Bedingungen Der COVID-19-Pandemie. Available: https://www. awmf.org/leitlinien/detail/ll/184-001.html

19 Stroeken K. Moral power: the magic of witchcraft. New York: Berghahn Books, 2010.

20 Geertz C. The interpretation of cultures: selected essays. 2000 edn. New York: Basic Books, 2000.

21 Biehl JG, Petryna A, eds. When people come first: critical studies in global health. Princeton: Princeton University Press, 2013.

22 Robinson LD, Cawthray JL, West SE. Ansine J Ten principles of citizen science. In: Hecker S, Haklay M, Bowser A, eds. Citizen science. Innovation in open science, society and policy. London: UCL Press, 2018: 27-40.

23 Coronavirus-Pandemie (SARS-CoV-2): Chronik bisheriger Maßnahmen und Ereignisse, 2020. Available: https://www.bundesge sundheitsministerium.de/coronavirus/chronik-coronavirus.html

24 Nübling M. Methoden zur Erfassung psychischer Belastungen: Erprobung eines Messinstrumentes (COPSOQ); [Abschlussbericht zum Projekt "Methoden zur Erfassung psychischer Belastungen Erprobung eines Messinstrumentes (COPSOQ)" - Projekt F 1885]. Bremerhaven: Wirtschaftsverl. NW Verl. für Neue Wiss, 2005.

25 Urquhart C. Grounded theory for qualitative research: a practical guide. Los Angeles, Calif; London: SAGE, 2013.

26 Holton JA. The coding process and its challenges. In: Bryant A Charmaz C, eds. The SAGE Handbook of grounded theory. London: Sage Publications, 2007: 65-289. 